\section{A comparison of the development of independence in two cohorts of young people with Down's syndrome}

\section{Billie Shepperdson}

\author{
Research Fellow \\ University College of Swansea \\ U.K.
}

\begin{abstract}
Studies in infancy, teens and the mid-twenties were made of an original cohort of children with Down's syndrome, born in the 60 s and brought up at home in South Wales. The young people continued to improve in their self-care and daily living skills into adulthood, although no one had reached full independence.
\end{abstract}

Studies were made in infancy and teens of a second comparative cohort of children with Down's syndrome, born in the 70s and brought up at home in South Wales. In the teens, significantly more of the comparative cohort were independent in their self-care skills and daily living skills compared with the original cohort when they were in their teens, nine years earlier. It was not that there were individuals in the comparative cohort who were superior to individuals in the original cohort, rather there were far fewer in the comparative cohort with extremely limited achievements who were not reaching their potential.

\section{Acknowledgements}

Thanks are due to the people with Down's syndrome who took part in the studies, their carers and the professionals who helped them.

The studies were funded by S.S.R.C. (1972 study), The Joseph Rowntree Memorial Trust (1981 studies), E.S.R.C. (Grant no. R000 23 2302) and The Leverhulme Trust (1990 studies).

(C) 1993, 1999. The Down Syndrome Educational Trust Down Syndrome Research and Practice 1994, 2 (1) 11-18

\section{Introduction}

The ability to take care of one's own personal needs has implications for a person's self-esteem, for the problem of care a person presents to their family, and the possibility of the person's acceptance into the community. Consequently the importance of men and women with Down's syndrome mastering self-care skills does not need stressing. Nowadays, even more is expected of young people: as well as being able to look after themselves in a domestic setting, parents hope that their children will be able to lead more autonomous lives. How realistic are these aims of parents, and how far have young people gone along this path by their late teens and mid-twenties?

The acquisition of self-care skills in childhood has been covered in earlier studies, e.g. Carr (1975), Cunningham (1982), Carr and Hewett (1982).

Until recently, there was little information on the abilities of older people with Down's syndrome, particularly if they lived at home. While Øster and Van den Tempel (1975) looked at all people with Down's syndrome living in one area in Denmark in 1949 and followed them up in 1959 and 1971, $63 \%$ of the subjects had been admitted to institutions and the information on those living at home is sometimes vague. For example, in 1971 all subjects were over 21 years old and 'most' could be left alone, although 'some' parents did not trust their off-spring. A third of mothers were prevented from taking outside jobs because of their caring responsibilities.

More detailed information on older people with Down's syndrome is available from later studies. Buckley and Sacks (1987) and Shepperdson (1988) have examined the abilities of teenagers. Carr (1988), following up her cohort, reported on 21 year olds. Holmes and Carr (1991), looking primarily at "the burden of care" gave details of some of the abilities of 20 adults with Down's syndrome aged 19-38 years (mean 28 years). Unfortunately their achievements are combined with those of 19 adults with autism and, although their abilities were not significantly different from those of the people with Down's syndrome, it means that comparison with other Down's syndrome studies is less satisfactory. Turner et al. (1991) found that self-sufficiency in 14-16 year olds was associated with mental age, excitability of the child, the presence of behaviour problems, the extent to which the mother used practical means of coping and the child's level of social activity.

This article provides more information on how far young people with Down's syndrome in their teens and twenties can look after themselves.

The situation for individuals with Down's syndrome has undergone dramatic change in the past decades. Expectations of what people with Down's syndrome can achieve and what services they need have risen, helped by the founding of the Down's Syndrome Association in the early seventies. Services have increased and improved. For example, there has been the introduction of various allowances, the Education Acts 1972 and 1981 and, more locally, The All Wales Strategy for Mentally Handicapped People began to be implemented in Wales in 1983. While it is difficult to disentangle cause and effect here - did increased expectations lead to better services or vice versa? - for whatever reason parents' expectations of their children with Down's syndrome have increased, and services have improved. The 
important question is, have these changed expectations and services produced improvements in the lives of the people with Down's syndrome and their families? More specifically, in the context of this article, have people with Down's syndrome nowadays improved in their ability to look after themselves as a result of all these efforts? Unfortunately, there is little information about the abilities of young adults with Down's syndrome from decades ago to help us make this comparison and, such data as there are, were often based on people who lived in institutions and so are not strictly comparable.

This article seeks to throw some light on this subject and examines how far a later generation of teenagers with Down's syndrome has different abilities compared with an earlier generation of teenagers with Down's syndrome.

\section{Aims of the study}

This study has the following aims.

1. To describe changes in the self-care abilities of a cohort of children with Down's syndrome from infancy to their mid-twenties to see how far their performance changes over the years and to see if there continue to be improvements into adulthood.
Table 1. Eating skills of the two cohorts.

\begin{tabular}{|l|l|l|l|l|l|}
\hline \multirow{2}{*}{ Help needed } & \multicolumn{3}{|c|}{ Original Cohort } & Comparative Cohort \\
\cline { 2 - 6 } & Infants & Teenagers & Adults & Infants & Teenagers \\
\hline None $^{*}$ & $27(73)$ & $44(83)$ & $45(87)$ & $18(69)$ & $24(92)$ \\
\hline Some & $8(22)$ & $6(11)$ & $4(18)$ & $6(23)$ & $2(8)$ \\
\hline Lot/always & $2(5)$ & $3(6)$ & $3(6)$ & $2(8)$ & - \\
\hline Total & $\mathbf{3 7 ( 1 0 0 )}$ & $\mathbf{5 3 ( 1 0 0 )}$ & $\mathbf{5 2 ( 1 0 1 )}$ & $\mathbf{2 6 ( 1 0 0 )}$ & $\mathbf{2 6 ( 1 0 0 )}$ \\
\hline
\end{tabular}

* Some help needed with cutting up

Comparison of teenagers who were independent in the two cohorts: not significant. (Figures in ()$=\%)$

Table 2. Dressing skills of the two cohorts.

\begin{tabular}{|l|l|l|l|l|l|}
\hline \multirow{2}{*}{ Help needed } & \multicolumn{3}{|c|}{ Original Cohort } & \multicolumn{1}{l|}{ Comparative Cohort } \\
\cline { 2 - 6 } & Infants & Teenagers & Adults & Infants & Teenagers \\
\hline None $^{*}$ & $8(22)$ & $12(23)$ & $17(33)$ & $6(23)$ & $14(54)$ \\
\hline Supervision & $22(60)$ & $8(15)$ & $13(25)$ & $13(50)$ & $6(23)$ \\
Some & $11(21)$ & $9(17)$ & & $3(12)$ \\
\hline Lot/always & $7(19)$ & $22(42)$ & $13(25)$ & $7(27)$ & $3(12)$ \\
\hline Total & $\mathbf{3 7 ( 1 0 1 )}$ & $\mathbf{5 3 ( 1 0 1 )}$ & $\mathbf{5 2 ( 1 0 1 )}$ & $\mathbf{2 6 ( 1 0 0 )}$ & $\mathbf{2 6 ( 1 0 1 )}$ \\
\hline
\end{tabular}

Comparison of teenagers who were independent in the two cohorts: $\chi^{2}=6.3$; d.f $=1 ; p<0.05$.

(Figures in ( ) = \%)
2. To compare the teenage self-care abilities of a cohort with Down's syndrome born in the early 70 s with those of a cohort born in the early $60 \mathrm{~s}$, who are also in their teens.

\section{Methods of Research}

The research is based on a series of longitudinal studies of two cohorts brought up at home in South Wales.

The individuals in the original cohort were born in 1964-66 and were seen in 1972 (infants), 1981 (teenagers) and 1990/1 (adults). There were only 37 children in the infant study but, by 1981, the number had risen to 53 because of improved co-operation of authorities and boundary changes. Two dropped out and one died. Unfortunately the infant sample had, by chance, a disproportionate number of less able individuals and so the infant studies are not strictly comparable with others. One young man had died by the time of the adult study.

The individuals in the comparative cohort were born in 1973-5 and were seen in 1981 (infants) and 1990/1 (teenagers). There were 26 children in this group.

The methods were the same in all studies: an interview with carers supplemented by the completion of the Gunzburg Progress Assessment Charts, Form 1 (all ages) and Form 2 (teenagers and adults only); the Reynell Language Scales (all ages); the English Picture Vocabulary Test (teenagers and adults only).
Information on participants' skills in self-care was collected from the main carer in the interview.

\section{Results}

\section{Self-care skills}

In this report, infants were treated a little more generously than teenagers or adults. For example, those who needed food to be cut up beforehand as infants are counted as independent, those who had a very occasional accident in toileting as infants are counted as independent.

\section{Eating}

Buckley and Sacks (1987) and Carr (1988) found that three quarters of both their 14-17 year olds and 21 year olds could eat independently, although some of the teenagers needed help cutting up food. Only $44 \%$ of Holmes and Carr's (1991) adults could eat completely without help.

Table 1 shows that in the original cohort more children became able to feed themselves as the years passed, although most - though not all - gains had been made before the adult years.

While a greater proportion of the comparative cohort teenagers were independent compared with the original cohort as teenagers, this difference did not reach significance. 
There were more problems associated with the physical act of eating in the original cohort - almost a fifth of the adults had some problem. Four of the most profoundly affected adults were inclined to 'shovel it in' or 'grab handfuls' if left unattended, four had problems with swallowing if food was not cut up small enough, one very able young man was extremely slow and this caused difficulties when he was in group activities, one person had no teeth and another needed more help because of poor eye sight. Two teenagers in the comparative cohort had problems with swallowing food and another needed help because of poor eyesight.

\section{Dressing}

Three quarters of Buckley and Sacks' (1987) teenagers were able to dress independently compared with about $60 \%$ of Carr's 21 year olds and 23\% of Holmes and Carr's (1991) group.

Again, it can be seen from Table 2 that, in the original cohort, improvements in the ability to dress independently continued into adulthood.

By the teenage years, the young people in the comparative cohort were showing superior abilities and significantly more were able to dress themselves, compared with the original cohort at the same stage.

There was a wide range of behaviour ranging from one man whose only contribution to the dressing process was to lift arms and legs, to others who were completely independent in this area. This variability is seen in most areas of ability.

\section{Toilet training}

Over $80 \%$ of Buckley and Sacks' (1987) teenagers were independent in their toilet habits, compared with three quarters of Carr's (1988) 21 year olds (who were also continent at nights) and 59\% of Holmes and Carr's (1991) adults.

Table 3 shows that abilities in the South Wales original cohort continued to improve as the children grew up although, again, improvements between the teens and adulthood were less marked than those made between infancy and teenage.

While a higher proportion of the teenagers in the comparative cohort were competent in toileting, compared with the original cohort as teenagers, the difference did not reach significance.

The most common difficulty was with wiping after bowel movement and the second most common problem was the tendency still to have accidents. However, even adults were felt to be able to improve - as one mother said, "we are getting there - at 25". One man needed enemas after a bowel infection in the past and one teenager had a colostomy. Both were unable to be independent because of these condi-
Table 4. Proportion of the two cohorts who wet the bed at night.

\begin{tabular}{|l|l|l|}
\hline & $\begin{array}{l}\text { Original } \\
\text { Cohort }\end{array}$ & $\begin{array}{l}\text { Comparative } \\
\text { Cohort }\end{array}$ \\
\hline Infants & $18(49)$ & $12(46)$ \\
\hline Teenagers & $12(23)^{1}$ & $7(27)^{2}$ \\
\hline Adults & $12(23)^{1}$ & - \\
\hline
\end{tabular}

13 doubly incontinent on occasion

${ }^{2} 2$ doubly incontinent on occasion

(Figures in ()$=\%$ ).

tions.

At night, the same proportions in both cohorts wet the bed as teenagers and there was no improvement in the original cohort from the teens to the twenties. One teenager had begun to wet the bed in the last two or three years but no cause had been found (Table 4). This is a higher proportion than in Buckley and Sacks' (1987) study where only 5\% continued to have problems at night.

\section{Bathing}

Buckley and Sacks (1987) reported that $80 \%$ of their $14-17$ year olds could bath independently, Carr (1988) over $60 \%$ of her 21 year olds, and only $31 \%$ in Holmes and Carr's (1988) older group.

Table 5. Bathing skills of the two cohorts.

\begin{tabular}{|l|l|l|l|}
\hline \multirow{2}{*}{ Help needed } & \multicolumn{2}{|c|}{ Original Cohort } & \multicolumn{1}{|c|}{$\begin{array}{c}\text { Comparative } \\
\text { Cohort }\end{array}$} \\
\cline { 2 - 4 } & Teenagers & Adults & Teenagers \\
\hline None & $15(28)$ & $24(66)$ & $13(50)$ \\
\hline Supervision & $9(17)$ & $4(8)$ & $5(19)$ \\
\hline Some & $1(2)$ & $3(6)$ & $1(4)$ \\
\hline Lot & $28(53)$ & $21(40)$ & $7(27)$ \\
\hline Total & $53(100)$ & $52(100)$ & $\mathbf{2 6 ( 1 0 0 )}$ \\
\hline
\end{tabular}

Comparison of teenagers who were independent in the two cohorts: not significant.

(Figures in ( ) =\%). 
Table 5 shows that young people in the original cohort continued to improve their abilities in bathing and that substantial gains were made in this area between teens and adulthood.

Table 5 also shows that the comparative teenagers were rather more independent in bathing than the original cohort had been at the same stage, but they had not attained the same levels of independence as the adults.

Some of the adults had developed strong reactions to bathing - about a fifth were regarded as extremely concerned with cleanliness and a similar proportion were very careless in such matters, or were afraid or reluctant to bath.

\section{Shaving}

Thirty seven percent of Holmes and Carr's (1991) adults could shave themselves.

Table 6. Shaving skills of the two cohorts.

\begin{tabular}{|l|l|l|l|}
\hline \multirow{2}{*}{ Help needed } & \multicolumn{2}{|c|}{ Original Cohort } & \multicolumn{1}{c|}{$\begin{array}{c}\text { Comparative } \\
\text { Cohort }\end{array}$} \\
\cline { 2 - 4 } & Teenagers & Adults & Teenagers \\
\hline None & $8(57)$ & $14(52)$ & $5(56)$ \\
\hline Some & $6(43)$ & $13(48)$ & $4(44)$ \\
\hline Total & $\mathbf{1 4 ( 1 0 0 )}$ & $\mathbf{2 7 ( 1 0 0 )}$ & $\mathbf{9 ( 1 0 0 )}$ \\
\hline
\end{tabular}

Comparison of teenagers who were independent in the two cohorts: not significant.

(Figures in ( ) = \%)

Table 6 shows that there were few differences between the cohorts in the ability of the young men and boys to shave.

\section{Care of periods}

While adults in the Holmes and Carr (1991) study have, on the whole, done less well than those in other studies in the ability to take care of their own periods, $61 \%$ were independent and this is better than either cohort at any age in South Wales. However, numbers of women were very small in the Holmes and Carr study - 13 out of 39.

Table 7. Independence at menstruation in the two cohorts.

\begin{tabular}{|l|l|l|l|}
\hline \multirow{2}{*}{ Help needed } & \multicolumn{2}{|c|}{ Original Cohort } & \multicolumn{1}{c|}{$\begin{array}{c}\text { Comparative } \\
\text { Cohort }\end{array}$} \\
\cline { 2 - 4 } & Teenagers & Adults & Teenagers \\
\hline None & $5(20)$ & $14(56)$ & $6(43)$ \\
\hline Supervision & $3(12)$ & $2(8)$ & $3(21)$ \\
\hline Some & $4(16)$ & - & - \\
\hline Lot/always & $13(52)$ & $9(26)$ & $5(36)$ \\
\hline Total & $\mathbf{2 5 ( 1 0 0 )}$ & $\mathbf{2 5 ( 1 0 0 )}$ & $\mathbf{1 4 ( 1 0 0 )}$ \\
\hline
\end{tabular}

Comparison of teenagers who were independent in the two cohorts: not significant.

(Figures in ()$=\%$ )
Table 7 shows that the original cohort made substantial gains in this area from the teens to adulthood.

Table 7 also shows that the comparative cohort were achieving more as teenagers than the original cohort (although not significantly so) but that, by adulthood, the original cohort were surpassing the performance of the comparative teenagers.

Most families dealt with this aspect of care with little fuss, although one adult was not sent to the Adult Training Centre at such times because they feared the staff could not cope. A teenager was not helped at College. One adult woman, who had previously been competent, had become careless in these matters and would not deal with her own periods or indeed bother to tell her carer when her periods started.

\section{Minding}

Seventeen percent of Carr's (1988) 21 year olds were never left in the house alone, $57 \%$ were left for periods of up to an hour, and $26 \%$ were left for 1.5 hours to all day.

Table 8. Staying in alone in the two cohorts.

\begin{tabular}{|l|l|l|l|}
\hline \multirow{2}{*}{$\begin{array}{l}\text { Time left } \\
\text { alone }\end{array}$} & \multicolumn{2}{|c|}{ Original Cohort } & $\begin{array}{l}\text { Comparative } \\
\text { Cohort }\end{array}$ \\
\cline { 2 - 4 } & Teenagers & Adults & Teenagers \\
\hline Never & $33(62)$ & $16(31)$ & $4(15)$ \\
\hline Up to 15 mins & $9(17)$ & $7(14)$ & $12(46)$ \\
\hline $15-120$ mins & $11(21)$ & $20(39)$ & $8(31)$ \\
Half day plus & & $9(17)$ & $2(8)$ \\
\hline Total & $\mathbf{5 3 ( 1 0 0 )}$ & $\mathbf{5 2 ( 1 0 1 )}$ & $\mathbf{2 6 ( 1 0 0 )}$ \\
\hline
\end{tabular}

Comparison of independent teenagers in the two cohorts:

$\chi^{2}=13.5 ;$ d.f. $=1 ; p<0.001$

(Figures is ()$=\%$ )

Table 8 shows that, for the adults, there was still a high proportion (almost a third) who were never left alone in the house for even the briefest of intervals. However, for those who were trusted, by adulthood, more were left alone for longer periods of time than they had been as teenagers.

The difference between the numbers of teenagers left alone in the house alone at all in the two cohorts is significantly different. Twenty two (85\%) of the comparative cohort were sometimes left alone at home, while this was so only for $38 \%$ of the original cohort in their teens.

In view of the fact that it is this constant need to provide, or arrange for, care which is most irksome for carers, it is important to ask the reasons for this unwillingness to leave the young people alone. The biggest concern for parents was the fear of the unexpected. It was felt that the young people would not necessarily respond appropriately to an out of the ordinary event. In this context the most mentioned and feared occurrence was that of someone coming to the door and most young people were told to ignore any callers. In fact, one very able young man in the original cohort who was living in an isolated spot had dealt very competently with suspicious callers and had telephoned the rural police. However, this had not reassured the mother that her son 
could indeed cope, and from being very relaxed she had become more restrictive. The other reason for this amount of care was the fear that the young people themselves would be too venturesome and so produce dangers for themselves. Other parents were aware that their grown up children would be uneasy or uncomfortable if left on their own.

No one felt able to leave the Down's syndrome person alone overnight, even the three who could leave their offspring alone all day with perhaps only a telephone call to check on their welfare.

\section{Going out alone}

Table 9 shows that the most difference between the teenage and adult years for the original cohort was that those who had been allowed out in their teens, extended their range in adulthood. There was only a slight increase in the proportion who were allowed out at all (45\% as teenagers to $52 \%$ as adults)

While similar proportions of the two cohorts were allowed to go out freely as teenagers, more of the comparative teenagers were allowed to experiment with limited amounts of freedom outside. The difference between the cohorts is not significantly different $(45 \%$ in the original cohort were allowed out at all compared with $65 \%$ in the comparative cohort).

Problems in going out were predictable. Traffic was a worry, especially if there were busy roads. Other people again were a barrier if they teased the person with Down's syndrome or if there were communication difficulties. Some parents had more general concerns about the gullibility of their youngsters. About $10 \%$ of subjects in each cohort were reluctant to go out and a similar proportion did not go out because there was nowhere to go.

One particularly sad example in the original cohort was a young man who had been allowed considerable freedom from infancy. This had been an intentional strategy by his mother, although it caused her considerable anxiety, to encourage maximum independence. In his teens he was remarkably independent and was able to go to town on his bike. By adulthood, the man was socially isolated and he went out much less because there were few attractive activities near by. Some that had existed - such as an unemployment club which ran leisure activities - had been discontinued because of short term funding of the project. His mother felt that her son had "discovered town and now he is not interested because he has done that".

One teenage boy in the comparative cohort had developed a fear of dogs. He became reluctant to go out. His mother had been unable to persuade him and a full problem had developed which was receiving help from the community mental handicap nurse.

Other people had more positive experiences and there were examples of adults who could use public transport to go to work and were able to go out on their own, or with friends, for relaxation.

\section{Total self-care skills}

Carr (1988) found that less than half of her 21 year olds were competent in all of four skill areas - feeding, dressing, toileting and bathing.

Table 10. Achievements in self-care of the two cohorts.

\begin{tabular}{|l|l|l|l|}
\hline \multirow{2}{*}{$\begin{array}{c}\text { Number } \\
\text { achieved }\end{array}$} & \multicolumn{2}{|c|}{ Original Cohort } & $\begin{array}{c}\text { Comparative } \\
\text { Cohort }\end{array}$ \\
\cline { 2 - 4 } & Teenagers & Adults & Teenagers \\
\hline 7 & $7(13)$ & $15(29)$ & $8(31)$ \\
\hline 6 & $2(4)$ & $4(8)$ & $4(15)$ \\
\hline 5 & $4(8)$ & $3(6)$ & $6(23)$ \\
\hline 4 & $8(15)$ & $8(15)$ & $1(4)$ \\
\hline 3 & $6(11)$ & $6(12)$ & $3(12)$ \\
\hline 2 & $8(15)$ & $3(6)$ & $2(8)$ \\
\hline 1 & $12(23)$ & $8(15)$ & $2(8)$ \\
\hline 0 & $6(11)$ & $5(10)$ & - \\
\hline Total & $\mathbf{5 3 ( 1 0 0 )}$ & $\mathbf{5 2 ( 1 0 1 )}$ & $\mathbf{2 6 ( 1 0 1 )}$ \\
\hline
\end{tabular}

Comparison of teenagers independent in 6 or more areas: $\chi^{2}=6.19 ;$ d.f. $=1 ; p<0.02$.

(Figures in ()$=\%$ )

Taking all the seven items considered in the earlier sections, there are significant differences between the two cohorts as teenagers. Significantly more of the comparative teenagers were achieving independence in at least six areas (Table 10).

\section{Daily living skills}

There is more to looking after oneself than the execution of basic self-care tasks. This section looks at the abilities of the young people in other areas where adults are usually independent.

\section{Choosing what to wear in the mornings}

Twenty four (45\%) of the original cohort had been involved in the decision of what to wear as teenagers and this had only 
risen by four to $28(54 \%)$ as the teenagers became adults.

In contrast, 17 (65\%) of the comparative cohort as teenagers were involved in these choices. Similar proportions in both cohorts as teenagers, however, were totally independent: $16(36 \%)$ in the original cohort and $7(27 \%)$ in the comparative cohort.

\section{Choosing clothes to buy}

Twenty four (45\%) of teenagers in the original cohort had been involved in discussions about what clothes to buy and this had risen to $27(52 \%)$ by adulthood. This compares with $54 \%$ of the comparative teenagers who were involved in these choices.

No teenagers in either cohort were given a completely free hand and this had not really changed for most of the adults. One mother said "I give him the money and he goes", but this was unusual and only a few people made genuinely independent choices. Far more parents remarked on the definite views of their son or daughter and their refusal to wear what they did not like, but exercising a veto is not the same as being given the freedom to choose independently. Some mothers were trying to give more freedom and, while offering advice, would say such things as "It's up to you, it's your money".
Table 11. Sleeping arrangements of the two cohorts.

\begin{tabular}{|l|l|l|l|l|l|}
\hline \multirow{2}{*}{ Sleeps } & \multicolumn{3}{|c|}{ Original Cohort } & \multicolumn{1}{l|}{ Comparative Cohort } \\
\cline { 2 - 6 } & Infants & Teenagers & Adults & Infants & Teenagers \\
\hline With carer(s) & $16(43)$ & $13(25)$ & $3(6)$ & $5(19)$ & $3(12)$ \\
\hline With others & $11(30)$ & $14(27)$ & $6(12)^{\star}$ & $4(15)$ & $2(8)$ \\
\hline Alone & $10(27)$ & $25(48)$ & $41(79)$ & $17(65)$ & $21(81)$ \\
\hline Residential & - & - & $2(4)$ & - & - \\
\hline Total & $\mathbf{3 7 ( 1 0 0 )}$ & $\mathbf{5 2 ( 1 0 0 )}$ & $\mathbf{5 2 ( 1 0 0 )}$ & $\mathbf{2 6 ( 9 9 )}$ & $\mathbf{2 6 ( 1 0 1 )}$ \\
\hline
\end{tabular}

* Own preference

Comparison of teenagers who sleep alone in the two cohorts: $\chi^{2}=6.37$; d.f. $=1 ; p<0.02$. (Figures in ( ) $=\%$ ).

Table 12. Bedtimes of the two cohorts.

\begin{tabular}{|c|c|c|c|c|c|}
\hline \multirow[b]{2}{*}{ Bedtimes } & \multicolumn{3}{|c|}{ Original Cohort } & \multicolumn{2}{|c|}{ Comparative Cohort } \\
\hline & Infants & Teenagers & Adults & Infants & Teenagers \\
\hline Before 6.59 & $9(24)$ & $2(4)$ & $1(2)$ & $9(35)$ & - \\
\hline 7.00-7.59 & $16(43)$ & $1(2)$ & - & $10(39)$ & - \\
\hline $\begin{array}{l}8.00-8.59 \\
9.00-9.59 \\
10.00-10.59 \\
\text { After } 11.00\end{array}$ & $6(16)$ & $\begin{array}{l}4(8) \\
23(43) \\
10(19) \\
1(2)\end{array}$ & $\begin{array}{l}2(4) \\
13(25) \\
19(37) \\
11(21)\end{array}$ & $4(15)$ & $\begin{array}{l}2(8) \\
10(39) \\
9(35) \\
4(15)^{\star}\end{array}$ \\
\hline No fixed time & $6(16)$ & $12(23)$ & $5(10)$ & $3(12)$ & $1(4)$ \\
\hline Total & 37 (99) & $53(101)$ & $51(99)$ & $26(101)$ & $26(101)$ \\
\hline
\end{tabular}

* For all $4,11.00 \mathrm{pm}$ was the latest time.

(Figures in ()$=\%$ ).

\section{Pocket money}

The same number of the original cohort as teenagers and adults had pocket money (42\%) and the same proportion of the comparative cohort teenagers $(42 \%)$ had pocket money. Only one of the comparative cohort had a large sum - $£ 25.00$ - and the maximum for the original cohort nine years earlier had been $£ 6.00$.

Of the adults, ten had amounts of over $£ 10.00$ per week and of the three who worked, two gave their parents $£ 15.00$ and $£ 25.00$ per week towards their keep (leaving £52.00 and $£ 65.00$ for spending, clothes and saving) and the other was given $£ 25.00$ per week by his mother. These people were exceptions, and, as we have seen, $42(81 \%)$ had amounts under $£ 10.00$ (mostly well under or none at all).

\section{Sleeping arrangements and bedtimes}

Table 11 shows, that over the years, the original cohort moved towards the more adult style at night of sleeping alone.

The comparative cohort achieved the same level of independence as the original cohort as adults much sooner. In their teens the sleeping patterns of the two cohorts were significantly different.

Table 12 shows a similar shift to more adult bedtimes in the original cohort. However, almost a third were still going to bed before $10.00 \mathrm{pm}$ which is probably somewhat early for most adults. Only five of the 16 who went early made their own choice of bedtime and one went at the same time as the whole family. Thirteen of the 16 who went after $11.00 \mathrm{pm}$ made their own choice. In all 30(59\%) chose what time to go to bed and five went at the same time as everybody else.

Looking at the two cohorts in the teens, the bulk of both went to bed before $9.00 \mathrm{pm}$ or between $9.00 \mathrm{pm}$ and $11.00 \mathrm{pm}$ but more of the original cohort had unusual or inappropriate bedtimes, given their age. Six of the comparative cohort chose their own bedtimes and more usually chose themselves.

\section{Using the telephone}

$7(27 \%)$ of the comparative teenagers could use the telephone and 20(39\%) of the original cohort adults. Data were not collected for the original cohort as teenagers.

\section{Using the bus}

No one in the original cohort could use the bus as a teenager but $11(21 \%)$ had had some experience of public transport by the time they were adults. Only 2 could actually use the bus transport system, rather than use a specific route which they had been trained to use. Unfortunately, some of these people had lost their skills when they no longer had to use the route they were used to. 
Two people in the comparative cohort could use the bus and two more were learning to do this.

\section{Housework}

Table 13. Help given in the house by the two cohorts.

\begin{tabular}{|l|l|l|l|}
\hline \multirow{2}{*}{ Helps } & \multicolumn{2}{|c|}{ Original Cohort } & $\begin{array}{c}\text { Comparative } \\
\text { Cohort }\end{array}$ \\
\cline { 2 - 4 } & Teenagers & Adults & Teenagers \\
\hline Often & $10(19)$ & $24(46)$ & $9(35)$ \\
\hline Sometimes & $27(51)$ & $8(15)$ & $7(27)$ \\
\hline Rarely & $6(11)$ & $6(12)$ & $4(15)$ \\
\hline Never & $10(19)$ & $4(8)$ & $6(23)$ \\
\hline Total & $\mathbf{5 3 ( 1 0 0 )}$ & $\mathbf{5 2 ( 1 0 0 )}$ & $\mathbf{2 6 ( 1 0 0 )}$ \\
\hline
\end{tabular}

(Figures in ( ) $=\%$ )

Table 13 shows the extent to which the young people helped in the house. More people in the original cohort helped in the house as adults than they did as teenagers and there was less 'token' helping in that those who did help usually did so regularly and efficiently. There was, however, some changing of categories. Fifteen helped more as adults and 9 helped less as adults. Those who did more, were the more able individuals (average Gunzburg Score 73.9) and those who did less tended not to be so able (average Gunzburg Score 37.1). It may be that carers had stopped making the effort to involve the less able.

Rather more of the comparative cohort gave help in the house in their teens but the differences were not great. As with the original cohort, girls were rather more helpful than boys.

\section{Conclusions}

Carr (1988) found that most progress in self-care skills was made before 11 years, but that some progress continued to be made into early adulthood. This study in South Wales adds support to this finding that progress continues beyond childhood, but is usually more limited. While the simpler and more often used skills - such as eating - are mastered early there is, not surprisingly, more delay in mastering more complex and less frequently executed tasks - such as bathing - and so there is more scope for improvements to continue into adulthood.

However, it has been shown that in most self-care areas, people with Down's syndrome born in the 70s were achieving self-care goals earlier than those who were born in the $60 \mathrm{~s}$. The failure to show significant differences between the cohorts in all self-care areas examined may simply be due to sample sizes: the trends were almost all in favour of the comparative cohort. As well, the comparative teenagers, as a group, were surpassing the achievements in self-care of the original cohort as adults in all but bathing and care of periods. It is this finding - of younger generations doing rather better than those which have gone before - which may help to explain why Holmes and Carr's (1991) adults fairly consistently showed lower abilities when compared with other studies of younger people with Down's syndrome.
Similar conclusions to those outlined above can be drawn for the other daily living skills that have been discussed in this paper. Those in the original cohort continued to make gains into adulthood. However, in all areas the comparative teenagers did better than, or the same as, the original cohort as teenagers. Not only that, in some areas they were doing better as teenagers than the original cohort were doing as adults i.e. in choosing their own clothes to wear, buying clothes, and in sleeping alone. Adults were doing better than teenagers in helping in the house, using the telephone and having had experience of using public transport.

These findings suggest that, for whatever reason, younger generations of teenagers are better able to look after their personal needs and have more normal lives. It can be speculated that these improvements are due to the efforts of carers, or services, which are making efforts to encourage independence. However, it must be pointed out that more people in the comparative group came from high social classes than in the original cohort (Shepperdson, 1985) and that high social class children with Down's syndrome - as with ordinary children - do better than those from lower social class backgrounds (Shepperdson, 1988). It may be that it is this relatively favoured home background that has produced a cohort with more advanced self care skills, rather than changes in attitudes or services.

These findings relate to groups of people with Down's syndrome and there is nothing in these results to suggest that improved services, or higher expectations of parents, or favoured social class backgrounds are producing later generations of more independent and resourceful individuals. There were examples of individuals with extremely high achievements in both cohorts, although the most exceptional person was in the original cohort. Rather it was that more individuals in the comparative cohort were being helped to achieve their potential and that there were fewer individuals (unlike in the original cohort) who were being over protected or who had not been encouraged to develop their potential. The fact that those in the original cohort were still making improvements indicates that it is not too late for some to rectify this situation, although this is not true for all.

\section{References}

Buckley,S. and Sacks,B. (1987)The adolescent with Down's syndrome. Life for the teenager and the family. Portsmouth Polytechnic.

Carr,J. (1975) Young children with Down's syndrome. London: Butterworths

Carr,J. (1988) Six weeks to twenty-one years old: a longitudinal study of children with Down's syndrome and their families. Journal of Child Psychology and Psychiatry, Vol. 29, no. 4, pp 407-431.

Carr,J. and Hewett,S. (1982) Children with Down's syndrome growing up: a preliminary report.Association of Child Psychology and Psychiatry Newsletter, Spring, 10-13.

Cunningham,C.C. (1982) Down's syndrome - a guide for parents. Souvenir Press.

Holmes,N. and Carr,J. (1991) The pattern of care in families of adults with a mental handicap: a comparison between families of autistic adults and Down's syndrome adults. Journal of Autism and Developmental Disorders. Vol 21, no. 2, 159-176.

Øster,J. and Van den Tempel,A. (1975) A 21 -year psychosocial follow up of 524 unselected cases of Down's syn- 
drome and their families. Acta Paediatrica Scandinavica 64. 505-513.

Shepperdson,B. (1985) Changes in the characteristics of families with Down's syndrome children. Journal of Epidemiology and Community Health, 39 (4), 320-324

Shepperdson,B.(1988) Growing up with Down's syndrome. Cassell.

Turner,S., Sloper,P., Krussen,C. and Cunningham,C.C. (1991) Factors relating to self-sufficiency in children with Down's syndrome. Journal of Mental Deficiency Research, 35, 13-24.

Address for correspondence:

Dr Billie Shepperdson,

Department of Psychology,

University College of Swansea, Singleton Park

Swansea, SA2 8PP. U.K.

\section{Understanding Down's Syndrome \\ A series of one-day workshops at The Sarah Duffen Centre}

- Meeting the educational needs of the child with Down's syndrome in the classroom

For teachers, special needs assistants, psychologists, parents

1 The special needs of the child with Down's syndrome

a) From 5 to 11 years - 19 April and 17 May

b) Teenagers - 14 June

2 Teaching the child with Down's syndrome - focus on the curriculum

a) In the infant school - 20 April

b) In the junior school - 18 May

c) In the secondary school - 25 May

- Understanding the development of children with Down's syndrome

For pre-school teachers, home-visitors, speech and language therapists, child development teams, parents.

1 Development from birth to 18 months - 11 May

2 Development from 18 months to 3 years - 8 June

3 Development from 3 to 5 years - 13 July

- Meeting the educational needs of children with Down's syndrome 13 April *

For educational psychologists, headteachers, LEA officers, special needs advisers

- Language and cognitive development in children with Down's syndrome 25 May

For speech and language therapists, psychologists, teachers

-Working with families

22 June

For social workers, health visitors, home-visitors, community teams, teachers, parents

- Screening for Down's syndrome - information for counsellors

20 July *

For midwives, obstetricians

- Sleep disturbance in children with Down's syndrome (half-day workshop)

12 October

For parents, health visitors, doctors, psychologists

The workshops will be organised and led by Sue Buckley, Principal Lecturer, Chartered Psychologist and Centre Director, with contributions from other Centre psychologists and professional colleagues as appropriate. Participants will be provided with written notes and guidance for further reading at all training days.

Prices are $£ 75.00$ (or $£ 100.00$ for those indicated by *) per day for professionals, or $£ 35$ per day for parents. Prices include buffet lunch, and tea and coffee at break times. A discount of $£ 10.00$ off the advertised prices of all one-day workshops is available for members of the Portsmouth Down's Syndrome Trust. The price of the half-day workshop on 12 October is $£ 35.00$ for professionals, $£ 17.50$ for parents, with a discount of $£ 5.00$ for members of PDST.

For further details and booking form, please contact the Sarah Duffen Centre, Belmont Street, Southsea, Hants, PO5 1NA. Tel: 0705824261 Fax: 0705824265. 